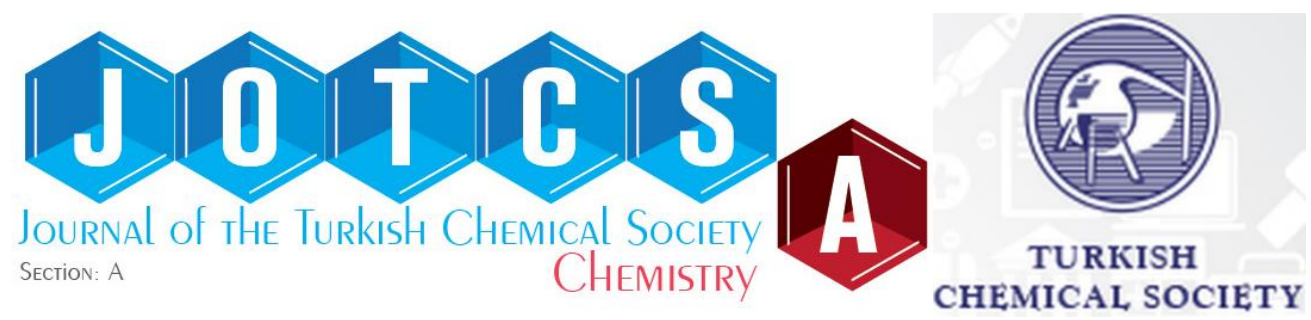

\title{
Allylation Of Aryl Grignard Reagents in the Presence of Transition Metal Catalysis and Organic Catalysis
}

\author{
Melike Kalkan ${ }^{1}$ \\ ${ }^{1}$ Ankara Üniversitesi Fen Fakültesi Kimya Bölümü, 06100 Beşevler/ Ankara
}

\begin{abstract}
The allylation yield and regioselectivity of phenyl Grignard reagent in THF was investigated in the presence of complexed transition metals and also uncomplexed or complexed transition metal salts. Additionally, the effect of Lewis acids and Lewis bases on the yield and the regioselectivity of the allylic arylation was also observed. Neither P-containing ligands for transition metal complexes, nor transition metal salts did make a difference on the yield and $\alpha: \gamma$ product ratio and gave the is $\alpha$-product as the main product. However, donor cosolvents resulted in decrease in the yield and change of the regioselectivity.
\end{abstract}

Keywords: Regioselectivity, Allylic arylation, Transition metal salts/complexes, Organic catalyst.

Submitted: June 2, 2017. Accepted: July 31, 2017.

Cite this: Kalkan M. Allylation Of Aryl Grignard Reagents in the Presence of Transition Metal Catalysis and Organic Catalysis. JOTCSA. 2017;4(3):877-888.

DOI: $10.18596 /$ jotcsa. 318333 .

*Corresponding author. E-mail: mkalkan@ankara.edu.tr. 
Kalkan, JOTCSA. 2017; 4(3): 877-888.

\section{INTRODUCTION}

Allylation of organometallic compounds in the presence of transition metal catalysis provides one of the most valuable methodologies for the formation of $\mathrm{C}-\mathrm{C}$ bonds (1-7).

Allylic coupling reactions are employed to prepare double bond containing compounds which attract much attention because of their various synthetic, biological and industrial applications $(8,9)$. In allylic coupling reactions, Grignard reagents are commonly used as partners since they are easier to use and they have advantages of high reactivity, easy preparation and functional group tolerance (10-15). So far, numerous reports have been reported on the regioselective allylation and stereoselective allylation of Grignard reagents (16-23).

In allylic coupling, the regioselectivity depends on the reaction parameters, i.e. type of Grignard reagent, allylic partner transition metal catalyst and organic catalyst as well as reaction conditions (24) (Scheme 1).

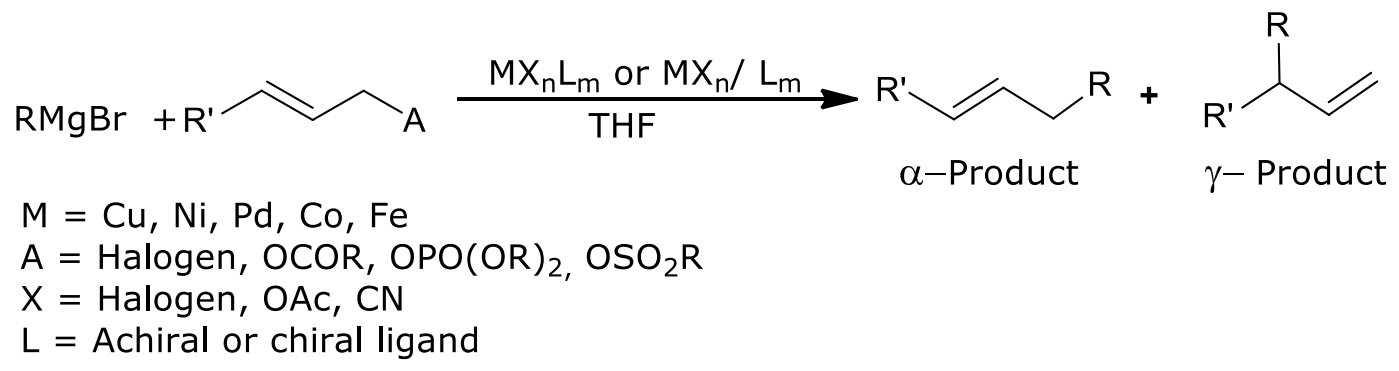

Scheme 1

Our group already worked on $\mathrm{Cu}(\mathrm{I})$ catalyzed allylic coupling of Grignard reagents in Barbier type reactions, i.e. magnesium is allowed to react with organyl halide and electrophile in one pot and then electrophile is reacted with in situ prepared Grignard reagent (25). We demonstrated that CuCN catalyzed alkyl-allyl coupling can be carried out under Barbier conditions with comparable yields and $\gamma$-selectivity to CuCN catalyzed allylation of clasically prepared alkyl Grignard reagents. Recently, we also reported succesful $\alpha$-selective nano CuO catalyzed allylation of in situ formed aryl Grignard reagents (26).

According to the best of our knowledge, the number of reports on the allylic coupling of aryl Grignard reagents are not as high as those of alkyl Grignard reagents. Mostly, enantioselective allylation reactions have been investigated. For regioselective allylation, a number of transition metal catalysts, such as Cu $(27-30)$, Ni $(31,32)$, Pd $(33,34)$, Co $(35,36)$ and Fe (37) have been used. However, much research has been directed to the use of different ligands for catalysts to see their effect on the outcome of the reaction. However, there are not reports on allylic coupling of clasically prepared Grignard reagents to compare the regioselectivity of transition metal 
Kalkan, JOTCSA. 2017; 4(3): 877-888.

catalysts. For this purpose, investigation of the effect of transition metal catalysis on the regioselectivity of allylation of arylmagnesium reagents was planned. Herein, details of the work to find out the optimum conditions for aryl-allyl coupling with transition metal catalysts and also organic catalysts is reported.

\section{MATERIALS AND METHODS}

All reactions were carried out in oven-dried glassware under a positive pressure of nitrogen using standard syringe-septum cap techniques (38). GC analyses were performed on a Thermo Finnigan gas chromatograph equipped with a ZB-5 capillary column packed with phenylpolysiloxane at $70-200{ }^{\circ} \mathrm{C}$ using the internal standard technique. THF was distilled from sodium benzophenonedianion. Bromobenzene and E-crotyl chloride were obtained commercially and used without purification. Magnesium turnings for Grignard reactions were used without purification. CuI, CuSCN (38), $\mathrm{CuBr}, \mathrm{CuCl}, \mathrm{CuCl}_{2}$ (39) and $\mathrm{CuCN}$ (40) were purified according to the published procedures, dried under reduced pressure and kept under nitrogen. Both $\mathrm{Cu}$ and $\mathrm{Ni}, \mathrm{Pd}, \mathrm{Co}, \mathrm{Ag}, \mathrm{Fe}$ catalysts were obtained commercially and kept under nitrogen.HMPA, NMP, DMF, DMPU, diglyme and TMEDA were distilled under reduced pressure and kept over molecular sieves under nitrogen. $\mathrm{MgCl}_{2}, \mathrm{ZnCl}_{2}$ and $\mathrm{LiCl}$ were dried under reduced pressure. Other Lewis acids and Lewis bases were obtained commercially and kept under nitrogen.

Phenylmagnesium bromide was prepared in THF according to standard procedure and its concentration was found by titration prior to use (41). For authentic samples, 1-phenyl-2-butene was purchased and 3-phenyl-1-butene was synthesized (42). Yields and product ratios are given as average of at least two experiments.

To PhMgBr reagent $(1.1 \mathrm{mmol})$, catalyst $(2 \% \mathrm{~mol}, 0.02 \mathrm{mmol})$ and/or Lewis base or Lewis acid (necessary equiv.) was added at $25^{\circ} \mathrm{C}$ and then $\mathrm{E}$-crotyl chloride $(1 \mathrm{mmol})$ was added dropwise. The mixture was stirred at $25^{\circ} \mathrm{C}$ for $1 \mathrm{~h}$. After addition of internal standard (nonane), the mixture was hydrolyzed with saturated $\mathrm{NH}_{4} \mathrm{Cl}$ solution. The aqueous phase was extracted with ether and aliquots were analyzed with GC to determine the coupling yield and $\alpha$-product: $\gamma$-product ratio of aryl coupling product.

\section{RESULTS AND DISCUSSION}

As a model reaction, allylation of phenylmagnesium bromide with $E$-crotyl chloride was chosen (Scheme 2). 
<smiles>C=CC(C)C(I)[P+]c1ccccc1</smiles>

Catalyst $=M X_{n}, M X_{n} L_{m}, M X_{n}+L, M L_{m}$ $\mathrm{M}=\mathrm{Cu}(\mathrm{I})$ and $\mathrm{Cu}(\mathrm{II}), \mathrm{Ni}(0)$ and $\mathrm{Ni}(\mathrm{II}), \mathrm{Pd}(0)$ and $\mathrm{Pd}(\mathrm{II}), \mathrm{Co}(\mathrm{II}), \mathrm{Ag}(\mathrm{I}), \mathrm{Fe}(\mathrm{II})$ and $\mathrm{Fe}(\mathrm{III})$ $\mathrm{L}=\mathrm{dppf}$, dppen, (c-Hex) ${ }_{3} \mathrm{P}, \mathrm{Ph}_{3} \mathrm{P}, \mathrm{t}-\mathrm{Bu}-\mathrm{P}_{4}$, PEPPSI-IPr, dba, COD Organic catalyst $=$ Lewis base and donor solvent, Lewis acid

\section{Scheme 2}

For comparison, uncatalyzed reaction in THF was also carried out and 98\% total yield and 92:8 $\alpha: \gamma$ ratio was obtained. Due to the different mechanisms of the catalysts, $\mathrm{Cu}(\mathrm{I}), \mathrm{Cu}(\mathrm{II}), \mathrm{Ni}$ (II) salts and $\mathrm{Cu}$ (II) and $\mathrm{Ni}$ (II) nano oxides were investigated firstly to find out the dependence of regioselectivity on the anion of the metal salt. However, $\alpha: \gamma$ ratio did not show any dependence on the metal and reactions, $\mathrm{Cu}$ and $\mathrm{Ni}$ salts were tried as catalyst to see the effect of the counter ion of the transition metal salt on the regioselectivity (Table 1). As seen, the coupling yield is medium to high and $\alpha: \gamma$ ratio is higher than $89: 19$ in $\mathrm{Cu}(\mathrm{I}), \mathrm{Cu}(\mathrm{II})$ and $\mathrm{Ni}(\mathrm{II})$ catalyzed aryl-allyl coupling.

Table 1. Regioselectivity in the allylation of $\mathrm{PhMgBr} \mathbf{1}$ with E-crotyl chloride $\mathbf{2}$ in THF in the presence of $\mathrm{Cu}(\mathrm{I}), \mathrm{Cu}(\mathrm{II})$ and $\mathrm{Ni}(\mathrm{II})$ catalysts ${ }^{\mathrm{a}, \mathrm{b}}$

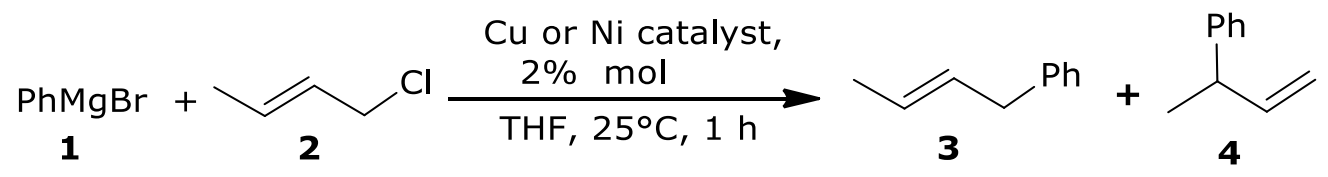

\begin{tabular}{clcc}
\hline Entry & Catalyst & ${\text { Coupling yield, } \mathbf{\%}^{\mathbf{c}}}$ & Regioselectivity $^{\mathbf{d}}$ \\
\hline 1 & - & 98 & $92: 8$ \\
2 & $\mathrm{CuI}$ & 83 & $90: 10$ \\
3 & $\mathrm{CuCl}$ & 74 & $91: 9$ \\
4 & $\mathrm{CuBr}$ & 77 & $91: 9$ \\
5 & $\mathrm{CuCN}$ & 73 & $91: 9$ \\
6 & $\mathrm{CuSCN}$ & 73 & $91: 9$ \\
7 & $\mathrm{Cu}(\mathrm{OAc})$ & 71 & $90: 10$ \\
8 & $\mathrm{Cu}(\mathrm{acac})_{2}$ & 91 & $89: 11$ \\
9 & $\mathrm{CuCl}$ & $93: 7$ \\
10 & $\mathrm{Cu}(\mathrm{II}) \mathrm{O}$ nano $^{\mathrm{e}}$ & 81 & $88: 12$ \\
11 & $\mathrm{Cu}\left(\mathrm{CF}_{3} \mathrm{SO}_{3}\right)_{2}$ & 70 & $90: 10$ \\
12 & $\mathrm{Cu}(\mathrm{OAc})_{2}$ & 74 & $89: 11$ \\
13 & $\mathrm{NiCl}$ (2) $_{12}$ & 53 & $81: 19$ \\
14 & $\mathrm{Ni}(\mathrm{II}) \mathrm{O}$ nano $^{\mathrm{e}}$ & 78 & $91: 9$ \\
15 & $\mathrm{Ni}(\mathrm{acac})_{2}$ & 49 & $80: 20$ \\
\hline
\end{tabular}

aThe data are averages of at least two independent experiments.

b Molar ratio of $\mathbf{1}: \mathbf{2}$ was optimized to be $2: 1$.

c The sum of GC yields of a-coupling product $\mathbf{3}$ and $y$-coupling product $\mathbf{4}$. The stereomer ratio $E: Z$ in $\mathbf{3}$ is not lower than 9:1.

$\mathrm{d}$ The ratio of GC yield of $\mathbf{3}$ and $\mathbf{4}$.

e nanopowder, $<50 \mathrm{~nm}$ particle size, Aldrich 
Kalkan, JOTCSA. 2017; 4(3): 877-888.

In the allylation, Lewis acids, $\mathrm{P}$-containing Lewis bases and $\mathrm{N}-, \mathrm{P}-$, or $\mathrm{O}$ - containing Lewis bases as donor solvents were also tried to see if a change could be obtained on the yield and regioselectivity has been summarized in Table 2. As P-containing Lewis bases, $\mathrm{Ph}_{3} \mathrm{P}$ (triphenylphosphine), dppf (diphenylphosphinoferrocene) and P4-t-Bu (phosphazene base) were used. As donor solvents, HMPA (hexamethylphosphoramide) and urotropine (Hexamethylenetetramine) were chosen. The main product is $\alpha$-product again in the presence of Lewis acids (entries 1-6). P-Containing Lewis bases, which are mostly used as ligands for transition metal complexes (entries 7-11) did not make a difference in the yield and $\alpha: \gamma$ product ratio. However, donor cosolvents (entries 12-13) resulted in decrease of yield and change of the regioselectivity.

In THF:HMPA ( $4: 1$ ), the yield did not change appreciably (entry 12) however as HMPA increases (i.e. THF:HMPA $=2: 1$ and $1: 1$ ), $\alpha: \gamma$ ratio decreases and mainly $\gamma$-selective allylation takes place (entries 13 and 14). Similarly, in THF:DMPU $(2: 1)$, the yield and also $\alpha: \gamma$ ratio decrease and the increase of cosolvent (THF:DMPU =1:1) results in a new decrease and almost $1: 1 \alpha: \gamma$ product ratio (entries 15 and 16). Unfortunately, in the presence of TMEDA, NMP, diglyme and DMF (entries 17-20) the reaction did not take place. The use of $\mathrm{Et}_{3} \mathrm{~N}, 2$,2'-bipyridyl and urotropine did not change the yield and $\alpha: \gamma$ ratio.

It was already reported that the use phosphine ligands together with transition metal catalysts caused change in the regioselectivity of the allylation. So monodentate phosphine ligands $\left(\mathrm{Ph}_{3} \mathrm{P}\right.$, $\left.(\mathrm{c}-\mathrm{Hex})_{3} \mathrm{P}\right)$ and bidentate diphosphine ligands (dppf, dppen) and transition metals and transition metal salts complexed with these ligands were also tried in the allylic coupling of phenylmagnesium bromide (Table 3 ). 
Kalkan, JOTCSA. 2017; 4(3): 877-888.

Table 2. Regioselectivity in the allylation of $\mathrm{PhMgBr} \mathbf{1}$ with $E$-crotyl chloride $\mathbf{2}$ in THF in the presence of Lewis acids and Lewis bases ${ }^{a, b}$

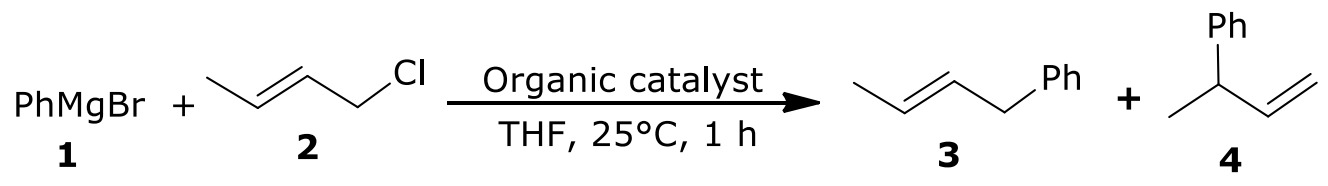

Organic catalyst $=$ Lewis base and donor solvent, Lewis acid

\begin{tabular}{|c|c|c|c|}
\hline Entry & Lewis acid or Lewis base, mol\% & Coupling yield, $\% c$ & Regioselectivityd \\
\hline 1 & $\mathrm{LiCl}, 5$ & 86 & $91: 9$ \\
\hline 2 & LiBr, 5 & 88 & $91: 9$ \\
\hline 3 & $\mathrm{MgCl}_{2}, 10$ & 94 & $91: 9$ \\
\hline 4 & $\mathrm{MgCl}_{2}, 10$ & 99 & $92: 8$ \\
\hline 5 & $\mathrm{ZnCl}_{2}, 5$ & 94 & $91: 9$ \\
\hline 6 & $\mathrm{ZnCl}_{2}$.TMEDA & 67 & $90: 10$ \\
\hline 7 & $\mathrm{Ph}_{3} \mathrm{P}, 2$ & 79 & $91: 9$ \\
\hline 8 & Dppf, 2 & 49 & $90: 10$ \\
\hline 9 & Dppen, 2 & 76 & $91: 9$ \\
\hline 10 & $(n-B u)_{3} P, 4$ & 73 & $93: 7$ \\
\hline 11 & P4-t-Bu, 4 & 75 & $88: 12$ \\
\hline 12 & $\mathrm{HMPA}^{\mathrm{e}}$ & 81 & $80: 20$ \\
\hline 13 & HMPA $^{f}$ & 87 & $37: 63$ \\
\hline 14 & HMPA $^{g}$ & 86 & $40: 60$ \\
\hline 15 & TMEDA $^{9}$ & 3 & $100: 0$ \\
\hline 16 & NMPg & 3 & $0: 100$ \\
\hline 18 & DMPUf & 60 & $75: 25$ \\
\hline 17 & DMPUg & 38 & $47: 53$ \\
\hline 19 & Diglyme & - & - \\
\hline 20 & $\mathrm{DMF}^{\mathrm{f}}$ & - & - \\
\hline 21 & $\mathrm{Et}_{3} \mathrm{~N}^{\mathrm{f}}$ & 61 & $90: 10$ \\
\hline 22 & 2,2'-Bipyridyl, 5 & 88 & $92: 8$ \\
\hline 23 & Urotropine, 5 & 84 & $90: 10$ \\
\hline
\end{tabular}

The data are averages of at least two independent experiments.

b Molar ratio of $\mathbf{1}: \mathbf{2}$ was optimized to be $2: 1$.

${ }^{c}$ The sum of GC yields of a-coupling product $\mathbf{3}$ and $y$-coupling product $\mathbf{4}$. The stereomer ratio $E: Z$ in $\mathbf{3}$ is not lower than 9:1.

$\mathrm{d}$ The ratio of GC yield of $\mathbf{3}$ and $\mathbf{4}$.

e THF: cosolvent $(\mathrm{v} / \mathrm{v})=4 / 1$.

${ }^{f}$ THF: cosolvent $(v / v)=2 / 1$.

${ }^{g}$ THF: cosolvent $(\mathrm{v} / \mathrm{v})=1 / 1$. 
Kalkan, JOTCSA. 2017; 4(3): 877-888.

Table 3. Regioselectivity in the allylation of $\mathrm{PhMgBr} \mathbf{1}$ with E-crotyl chloride $\mathbf{2}$ in THF in the presence of transition metal catalyst and/or phosphine ligand ${ }^{a, b}$<smiles>C=CC(C[PH2+]c1ccccc1)c1ccccc1</smiles>

$\mathrm{M}=\mathrm{Cu}(\mathrm{I})$ and $\mathrm{Cu}(\mathrm{II}), \mathrm{Ni}(0)$ and $\mathrm{Ni}(\mathrm{II}), \mathrm{Pd}(0)$ and $\mathrm{Pd}(\mathrm{II}), \mathrm{Co}(\mathrm{II}), \mathrm{Ag}(\mathrm{I}), \mathrm{Fe}(\mathrm{II})$ and $\mathrm{Fe}(\mathrm{III})$ $\mathrm{L}=\mathrm{dppf}$, dppen, (c-Hex) $)_{3} \mathrm{P}, \mathrm{Ph}_{3} \mathrm{P}$, t-Bu-P4, PEPPSI-IPr, dba, COD

\begin{tabular}{|c|c|c|c|}
\hline Entry & Catalyst & Coupling yield, $\% c$ & Regioselectivity $^{d}$ \\
\hline 1 & $\mathrm{CuCl}+\mathrm{Ph}_{3} \mathrm{P}$ & 68 & $90: 10$ \\
\hline 2 & $\mathrm{CuCl}+(\mathrm{c}-\mathrm{Hex})_{3} \mathrm{P}$ & 75 & $89: 11$ \\
\hline 3 & $\mathrm{CuCl}+\mathrm{dppf}$ & 79 & $90: 10$ \\
\hline 4 & $\mathrm{CuCl}+$ dppen & 71 & $90: 10$ \\
\hline 5 & $\mathrm{CuCl}+\mathrm{P} 4-\mathrm{t}-\mathrm{Bu}$ & 77 & $90: 10$ \\
\hline 6 & $\mathrm{CuCl}_{2}+\mathrm{Ph}_{3} \mathrm{P}$ & 69 & $90: 10$ \\
\hline 7 & $\mathrm{CuCl}_{2}+\mathrm{dppf}$ & 75 & $91: 9$ \\
\hline 8 & $\mathrm{NiCl}_{2}\left(\mathrm{Ph}_{3} \mathrm{P}\right)_{2}$ & 71 & $68: 32$ \\
\hline 9 & $\mathrm{NiCl}_{2}(\mathrm{c}-\mathrm{Hex})_{3} \mathrm{P}$ & 68 & $71: 29$ \\
\hline 10 & $\mathrm{NiCl}_{2}+\mathrm{n}-\mathrm{Bu}_{3} \mathrm{P}$ & 44 & $86: 14$ \\
\hline 11 & $\mathrm{NiCl}_{2}$ (dppf) & 78 & $56: 44$ \\
\hline 12 & $\mathrm{NiCl}_{2}+\mathrm{dppen}$ & 49 & $67: 33$ \\
\hline 13 & $\mathrm{Ni}(C O D)_{2}$ & 74 & $88: 12$ \\
\hline 14 & $\mathrm{PdCl}_{2}+\mathrm{Ph}_{3} \mathrm{P}$ & 63 & $62: 38$ \\
\hline 15 & $\mathrm{PdCl}_{2}(\mathrm{dppf})$ & 68 & $82: 18$ \\
\hline 16 & PEPPSI-IPr & 20 & $100: 0$ \\
\hline 17 & $\mathrm{Pd}\left(\mathrm{Ph}_{3} \mathrm{P}\right)_{4}$ & 73 & $86: 14$ \\
\hline 18 & $\mathrm{Pd}(\mathrm{OAC})_{2}+2 \mathrm{Ph}_{3} \mathrm{P}$ & 52 & $83: 17$ \\
\hline 19 & $\mathrm{Pd}(\mathrm{OAC})_{2}+\mathrm{dppf}$ & 45 & $84: 16$ \\
\hline 20 & $\mathrm{Pd}(\mathrm{dba})_{2}$ & 60 & $95: 5$ \\
\hline 21 & $\mathrm{CoCl}_{2}+2 \mathrm{Ph}_{3} \mathrm{P}$ & 64 & 91:9 \\
\hline 22 & $\mathrm{CoCl}_{2}+2\left(\mathrm{c}-\mathrm{Hex}_{3} \mathrm{P}\right)$ & 65 & $89: 11$ \\
\hline 23 & $\mathrm{CoCl}_{2}+\mathrm{dppf}$ & 57 & $79: 21$ \\
\hline 24 & $\mathrm{CoCl}_{2}+\mathrm{dppen}$ & 60 & $87: 13$ \\
\hline 25 & $\mathrm{AgI}+2 \mathrm{Ph}_{3} \mathrm{P}$ & 88 & $93: 7$ \\
\hline 26 & $\mathrm{AgI}+2\left(\mathrm{c}-\mathrm{Hex}_{3} \mathrm{P}\right)$ & 81 & $93: 7$ \\
\hline 27 & AgI+dppf & 75 & $92: 8$ \\
\hline 28 & AgI+dppen & 73 & $92: 8$ \\
\hline 29 & $\mathrm{Ag}\left(\mathrm{CF}_{3} \mathrm{SO}_{3}\right)+2 \mathrm{Ph}_{3} \mathrm{P}$ & 79 & $91: 9$ \\
\hline 30 & $\mathrm{FeCl}_{2}+2 \mathrm{Ph}_{3} \mathrm{P}$ & 59 & $76: 24$ \\
\hline 31 & $\mathrm{Fe}(\mathrm{acac})_{2}+2 \mathrm{Ph}_{3} \mathrm{P}$ & 23 & $57: 43$ \\
\hline 32 & $\mathrm{Fe}(\mathrm{acac})_{2}+\mathrm{dppf}$ & 18 & $50: 50$ \\
\hline 33 & $\mathrm{FeCl}_{3}+2 \mathrm{Ph}_{3} \mathrm{P}$ & 22 & $59: 41$ \\
\hline 34 & $\mathrm{FeCl}_{3}+\mathrm{dppf}$ & 20 & $55: 45$ \\
\hline
\end{tabular}

aThe data are averages of at least two independent experiments.

b Molar ratio of $\mathbf{1}: \mathbf{2}$ was optimized to be $2: 1$.

${ }^{c}$ The sum of GC yields of a-coupling product $\mathbf{3}$ and $y$-coupling product $\mathbf{4}$. The stereomer ratio $E: Z$ in $\mathbf{3}$ is not lower than 9:1.

d The ratio of GC yield of $\mathbf{3}$ and $\mathbf{4}$.

As seen, the use of these ligands as organic catalysts in the presence of $\mathrm{CuCl}$ and $\mathrm{CuCl}_{2}$ did not make a change in the outcome of the reaction (entries 1-7). However $\mathrm{NiCl}_{2}$ complexed with a phosphine (entries 8,9 and 11 ) caused a decrease in $\alpha: \gamma$ ratio. Use of phosphines in the presence of $\mathrm{NiCl}_{2}$ (entries 10 and 12 ) led to a much decrease in the yield. $\mathrm{Ni}(\mathrm{COD})_{2}$ was also tried as a catalyst ( $C O D=1,5$-cyclooctadiene), but did not give a difference in the outcome of the reaction (entry 13). 
No remarkable change in the regioselectivity was observed in the allylation catalyzed with Pd complexes and $\mathrm{PdCl}_{2}$ complexes (entries 14,15,17 and 20). However the use of $\mathrm{Ph}_{3} \mathrm{P}$ or dppf in the presence of $\mathrm{Pd}(\mathrm{OAc})_{2}$ (entries 18 and 19) decreased the yield and catalytic activity of PEPPSIIPr resulted in a quite low yield (entry 16$). P d(d b a)_{2}$ was also tried as a catalyst ( $d b a=$ dibenzylideneacetone) (entry 20). Allylation in the presence of $\mathrm{CoCl}_{2}$ and a phosphine ligand gave somewhat lower yield, but did not change the regioselectivity (entries 21-24). Agcatalyzed allylation in the presence of phosphines gave quite similar results to those obtained by $\mathrm{Cu}$ and phosphine catalyzed allylation (entries 25-29). The presence of phosphine in the allylation catalyzed $\mathrm{FeCl}_{2}$ did not result in much change of yield and regioselectivity (entry 30 ). However, the catalytic activity of $\mathrm{Fe}(\mathrm{acac})_{2}$ in the presence of a phosphine decreased the yield remarkably and gave an $\alpha: \gamma$ ratio of $\sim 1: 1$.

\section{CONCLUSIONS}

In this study, the catalytic activities of $\mathrm{Cu}(\mathrm{I}), \mathrm{Cu}(\mathrm{II}), \mathrm{Ni}(0), \mathrm{Ni}(\mathrm{II}), \mathrm{Pd}(0), \mathrm{Pd}(\mathrm{II}), \mathrm{Co}(\mathrm{II}), \mathrm{Ag}(\mathrm{I})$ and $\mathrm{Fe}(\mathrm{II})$, either complexed or in the presence of phosphines and the catalytic activities of Lewis acids and Lewis bases as organic catalyst in the allylation of aryl Grignard reagents was investigated in detail. It was observed that Lewis bases and transition metal salt/phosphine complexes or phosphine complexed transition metal salts resulted in change in the yield and regioselectivity.

\section{ACKNOWLEDGMENTS}

I am grateful to my PhD supervisor, Prof. Dr. Ender Erdik, for her help in the preparation of this paper.

\section{REFERENCES}

1. Diederich F, Stang PJ. Metal-catalyzed cross-coupling reactions. New York: Wiley-VCH; 1998. 517 p.

2. Lipshutz BH, editor. Organometallics in synthesis: fourth manual. Hoboken, New Jersey: Wiley; 2013. $555 \mathrm{p}$.

3. Negishi E, Liu F. Palladium-Catalyzed Cross-Coupling between Allyl, Benzyl, or Propargyl Groups and Unsaturated Groups. In: Negishi E, editor. Handbook of Organopalladium Chemistry for Organic Synthesis [Internet]. New York, USA: John Wiley \& Sons, Inc.; 2002 [cited 2017 Aug 18]. p. 551-89. Available from: http://doi.wiley.com/10.1002/0471212466.ch24

4. de Meijere A, Diederich F, editors. Metal-Catalyzed Cross-Coupling Reactions [Internet]. Weinheim, Germany: Wiley-VCH Verlag GmbH; 2004 [cited 2017 Aug 18]. Available from: http://doi.wiley.com/10.1002/9783527619535 
Kalkan, JOTCSA. 2017; 4(3): 877-888.

5. Takahashi T, Kanno K. Nickel-Catalyzed Cross-Coupling Reactions. In: Tamaru $Y$, editor. Modern Organonickel Chemistry [Internet]. Weinheim, FRG: Wiley-VCH Verlag GmbH \& Co. KGaA; 2005 [cited 2017 Aug 18]. p. 41-55. Available from: http://doi.wiley.com/10.1002/3527604847.ch2

6. Shintani R, Hayashi T. Asymmetric Synthesis. In: Tamaru Y, editor. Modern Organonickel Chemistry [Internet]. Weinheim, FRG: Wiley-VCH Verlag GmbH \& Co. KGaA; 2005 [cited 2017 Aug 18]. p. 24072. Available from: http://doi.wiley.com/10.1002/3527604847.ch9

7. Jana R, Pathak TP, Sigman MS. Advances in Transition Metal (Pd,Ni,Fe)-Catalyzed Cross-Coupling Reactions Using Alkyl-organometallics as Reaction Partners. Chemical Reviews. 2011 Mar 9;111(3):1417-92.

8. Kar A, Argade NP. A Concise Account of Recent S N 2' Grignard Coupling Reactions in Organic Synthesis. Synthesis. 2005;2005(18):2995-3022.

9. Lu Z, Ma S. Metal-Catalyzed Enantioselective Allylation in Asymmetric Synthesis. Angewandte Chemie International Edition. 2008 Jan;47(2):258-97.

10. Silverman GS, Rakita PE, editors. Handbook of Grignard reagents. New York: Marcel Dekker; 1996. 708 p. (Chemical industries).

11. Lipshutz BH, Sengupta S. Organocopper Reagents: Substitution, Conjugate Addition, Carbo/Metallocupration, and Other Reactions. In: John Wiley \& Sons, Inc., editor. Organic Reactions [Internet]. Hoboken, NJ, USA: John Wiley \& Sons, Inc.; 1992 [cited 2017 Aug 18]. p. 135-631. Available from: http://doi.wiley.com/10.1002/0471264180.or041.02

12. van der Molen NC, Tiemersma-Wegman TD, Fañanás-Mastral $M$, Feringa $B L$. Regio-and enantioselective copper-catalyzed allylic alkylation of ortho-substituted cinnamyl bromides with Grignard reagents. The Journal of organic chemistry. 2015;80(10):4981-4984.

13. Langlois J-B, Alexakis $A$. Copper-catalyzed enantioselective allylic substitution. In: Transition Metal Catalyzed Enantioselective Allylic Substitution in Organic Synthesis. Springer; 2011. p. 235-268.

14. Alexakis A, Krause N, Woodward S, editors. Copper-Catalyzed Asymmetric Synthesis: Alexakis/CopperCatalyzed Asymmetric Synthesis [Internet]. Weinheim, Germany: Wiley-VCH Verlag GmbH \& Co. KGaA; 2014 [cited 2017 Aug 18]. Available from: http://doi.wiley.com/10.1002/9783527664573

15. Huang $Y$, Fañanás-Mastral $M$, Minnaard AJ, Feringa BL. A novel catalytic asymmetric route towards skipped dienes with a methyl-substituted central stereogenic carbon. Chemical Communications. 2013;49(32):3309.

16. Krause N, editor. Modern organocopper chemistry. Weinheim: Wiley-VCH; 2002. 377 p.

17. Giannerini M, Fañanás-Mastral M, Feringa BL. Z- Selective Copper-Catalyzed Asymmetric Allylic Alkylation with Grignard Reagents. Journal of the American Chemical Society. 2012 Mar 7;134(9):410811.

18. Alexakis A, Malan C, Lea L, Tissot-Croset $K$, Polet D, Falciola C. The Copper-Catalyzed Asymmetric Allylic Substitution. CHIMIA International Journal for Chemistry. 2006 Mar 28;60(3):124-30. 
Kalkan, JOTCSA. 2017; 4(3): 877-888.

19. Tominaga $S$, Oi $Y$, Kato $T$, An DK, Okamoto $S$. $Y$-Selective allylic substitution reaction with Grignard reagents catalyzed by copper $\mathrm{N}$-heterocyclic carbene complexes and its application to enantioselective synthesis. Tetrahedron letters. 2004;45(29):5585-5588.

20. Tissot-Croset $K$, Polet $D$, Alexakis A. A Highly Effective Phosphoramidite Ligand for Asymmetric Allylic Substitution. Angewandte Chemie International Edition. 2004 Apr 26;43(18):2426-8.

21. Falciola CA, Alexakis A. Copper-Catalyzed Asymmetric Allylic Alkylation. European Journal of Organic Chemistry. 2008 Aug;2008(22):3765-80.

22. Harutyunyan $S R$, den Hartog $T$, Geurts $K$, Minnaard AJ, Feringa BL. Catalytic Asymmetric Conjugate Addition and Allylic Alkylation with Grignard Reagents. Chemical Reviews. 2008 Aug;108(8):2824-52.

23. Alexakis A, Backvall J, Krause N, Pàmies O, Diéguez M. Enantioselective copper-catalyzed conjugate addition and allylic substitution reactions. Chemical reviews. 2008;108(8):2796-2823.

24. Falciola CA, Tissot-Croset $K$, Alexakis A. $\beta$-Disubstituted Allylic Chlorides: Substrates for the $\mathrm{Cu}$ Catalyzed Asymmetric SN2' Reaction. Angewandte Chemie International Edition. 2006;45(36):59955998.

25. Erdik E, Koçoğlu M. Copper catalyzed magnesium-Barbier reaction for $\gamma$-selective alkyl-allyl coupling. Tetrahedron letters. 2007;48(24):4211-4214.

26. Kalkan M., Erdik E. and Ömür Pekel Ö. Revisiting Allylic Coupling of Grignard Reagents. Nano Copper Catalyzed One-Pot $\alpha$-Selective Aryl-Allyl Coupling, Organic Preparations and Procedures International, Accepted.

27. Kiyotsuka Y, Acharya HP, Katayama Y, Hyodo T, Kobayashi Y. Picolinoxy Group, a New Leaving Group for anti SN2' Selective Allylic Substitution with Aryl Anions Based on Grignard Reagents. Organic letters. 2008;10(9):1719-1722.

28. Kiyotsuka $Y$, Katayama $Y$, Acharya HP, Hyodo $T$, Kobayashi $Y$. New general method for regio-and stereoselective allylic substitution with aryl and alkenyl coppers derived from Grignard reagents. The Journal of organic chemistry. 2009;74(5):1939-1951.

29. Feng $C$, Kobayashi Y. Allylic Substitution for Construction of a Chiral Quaternary Carbon Possessing an Aryl Group. The Journal of organic chemistry. 2013;78(8):3755-3766.

30. Feng $C$, Kobayashi $Y$. Installation of a Chiral Side Chain to a 2-Alkylidene-1-cycloalkan-1-ol Unit by Using Allylic Substitution. European Journal of Organic Chemistry. 2013;2013(29):6666-6676.

31. Didiuk MT, Morken JP, Hoveyda AH. Phosphine-directed stereo-\& regioselective Ni-catalyzed reactions of Grignard reagents with allylic ethers. Tetrahedron. 1998;54(7):1117-1130.

32. Hayashi T. M. Konishi, K.-I. Yokota and M. Kumada. J Organomet Chem. 1985;285:359.

33. Takuma $\mathrm{Y}$, Imaki $\mathrm{N}$. Novel phosphine-palladium complex-catalysed regioselective allylation of a Grignard reagent. Journal of molecular catalysis. 1993;79(1-3):1-5.

34. Volla CMR, Dubbaka $S R$, Vogel P. Palladium-catalyzed desulfinylative $C-C$ allylation of Grignard reagents and enolates using allylsulfonyl chlorides and esters. Tetrahedron. 2009;65(2):504-511. 
Kalkan, JOTCSA. 2017; 4(3): 877-888.

35. Yasui H, Mizutani K, Yorimitsu H, Oshima K. Cobalt- and rhodium-catalyzed cross-coupling reaction of allylic ethers and halides with organometallic reagents. Tetrahedron. 2006 Feb;62(7):1410-5.

36. Mizutani K, Yorimitsu H, Oshima K. Cobalt-Catalyzed Allylic Substitution Reaction of Allylic Ethers with Phenyl and Trimethylsilylmethyl Grignard Reagents. Chemistry Letters. 2004 Jul;33(7):832-3.

37. Qi L, Ma E, Jia F, Li Z. Iron-catalyzed allylic substitution reactions of allylic ethers with Grignard reagents. Tetrahedron Letters. 2016 May;57(20):2211-4.

38. Leonard J, Lygo B, Procter L. Advanced practical organic chemistry. 2. ed. London: Blackie Academic \& Professional; 1995. $298 \mathrm{p}$.

39. Perrin DD, Armarego WLF. Purification of laboratory chemicals. 3rd ed. Oxford; New York: Pergamon Press; 1988. 391 p.

40. Barber HJ, Schönberg A, Mustafa A. Notes. J Chem Soc. 1943;0(0):79-80.

41. Watson SC, Eastham JF. Colored indicators for simple direct titration of magnesium and lithium reagents. Journal of Organometallic Chemistry. 1967;9(1):165-168.

42. Kalkan M, Erdik E. Reactivity of mixed organozinc and mixed organocopper reagents: 14. Phosphinenickel catalyzed aryl-allyl coupling of (n-butyl)(aryl) zincs. Ligand and substrate control on the group selectivity and regioselectivity. Journal of Organometallic Chemistry. 2016;818:28-36. 
